\title{
Asimetrías y diversidad en las relaciones naturaleza-cultura: una reflexión en torno a la modernidad occidental
}

\author{
$\longrightarrow$ \\ Asymmetries and Diversity in \\ Nature-Culture Relations: a Reflection on Western Modernity \\ Eleder Piñeiro Aguiar* \\ (D) : http://orcid.org/0000-0001-6770-7180
}

Tipo de Artículo: Informes de Investigación y ensayos inéditos

Doi: 10.17533/udea.unipluri.19.1.05

Cómo citar este artículo:

Piñero Aguiar, E. (2019). Asimetrías y diversidad en las relaciones naturaleza-cultura: una reflexión en torno a la modernidad occidental. Uni-pluriversidad, 19(1), 72-86. Doi: 10.17533/udea.unipluri.19.1.05

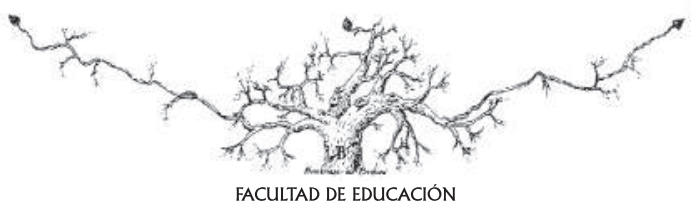

Recibido: 2018-09-29 • Aprobado: 2019-08-02

* Profesor Universidade da Coruña, España. Licenciado en Sociología; Máster en Migraciones Internacionales; Doctor en Antropología.

E-mail: elederpa1983@gmail.com 


\title{
Resumen
}

En este texto de carácter exploratorio desarrollo una genealogía acerca de la visión que diferentes autores y teorías occidentales han desarrollado en torno a la idea de naturaleza y su relación con el progreso, desde la filosofía clásica hasta la modernidad eurocéntrica. A continuación, contrapongo lo que considero un imaginario universal en torno a las relaciones naturaleza-cultura con otras investigaciones procedentes del Sur global y en particular diversas teorizaciones indigenistas, latinoamericanas y decoloniales. En consecuencia, desarrollo una revisión documental en torno a textos "clásicos" y actuales, concluyendo que el individualismo y desarrollismo emanados de la tradición occidental encuentran fracturas, resistencias y puntos de fuga planteados desde perspectivas académicas y activistas que articulan un discurso contrario al extractivismo epistémico y materialista eurocéntrico.

Palabras Clave: Conocimiento. Racionalidad. Occidente. Ciencia. Sur global.

\begin{abstract}
In this exploratory paper I develop a genealogy about the vision that different Western authors and theories have developed around the idea of nature and its relation to progress, from classical philosophy to Eurocentric modernity. Then, I contrast what I consider a universal imaginary about nature-culture relations with other research from the global South and in particular from various indigenous, Latin American and decolonial theories. Therefore, a documentary review has been developed around "classic" and current texts. This paper concludes that individualism and developmentalism coming from the Western tradition find fractures, resistances and vanishing points raised from academic and activist perspectives that articulate a discourse contrary to Eurocentric epistemic and materialist extractivism.
\end{abstract}

Keywords: Knowledge. Rationality. West. Science. Global South. 


\section{INTRODUCCIÓN}

Cuando le preguntaron a Ghandi qué le parecía la civilización occidental él respondió que sería una buena idea ${ }^{1}$. Retóricas aparte, si se permite una metáfora biologicista inicial, la doble hélice del ADN epistemológico de dicha civilización occidental tiene dos cadenas: por una parte la judeocristiana y por otra parte la grecolatina. A lo largo de este texto, fruto de una investigación con fuentes secundarias llevada a cabo en mi etapa de docente de filosofía en la Universidad Adolfo Ibáñez de Chile (diciembre 2017-agosto 2018), me centraré en la segunda cadena para exponer cómo ha sido la relación de la civilización/cultura con la naturaleza, sin obviar que en el texto bíblico (cadena judeocristiana) ya nos encontramos con una sentencia que será fundadora de la intervención humana en el ambiente natural: "y tenga dominio sobre los peces del mar y los volátiles del cielo y sobre los demás animales que carecen de razón" (Génesis 1: 26). Como punto de partida se comenta que esta investigación fue motivada por la lectura de textos clásicos del pensamiento occidental, objeto de análisis de materias ${ }^{2}$ que impartía en el periodo comentado, de dónde surgió la pregunta acerca de cómo la teorización surgida desde Sócrates hasta nuestros días ha venido observando la relación entre naturaleza y cultura.

Volviendo a la tradición judeocristiana he de decir que hasta tal punto hubo continuidad desde las sagradas escrituras hasta autores cristianos, quienes integraron razón y fe en sus análisis, que ya San Agustín (2004, p. 104) en el Siglo III expone que los seres irracionales y las plantas "por justísima ordenación del Creador su vida y su muerte están subordinadas a nuestros usos". Incluso más adelante (San Agustín, 2004, p. 535) afirma: "de ese Dios uno, verdadero y óptimo, procede tanto la naturaleza, por la que somos imagen suya, como la ciencia, por la que le conocemos y nos conocemos". Además, según San Agustín, pecar es acercarse a las bestias, lo cual supone un alejamiento y contravención de ser la imagen de Dios, y, por lo tanto, algo que debe evitarse a toda costa.

Lo referido por el autor de "Ciudad de Dios" ha sido una constante en todo el pensamiento occidental, desde Platón y Aristóteles hasta la modernidad fundada por Descartes: mostrar qué nos hace humanos, racionales y por tanto, diferentes del mundo animal. Siglos más adelante Santo Tomás, padre de la escolástica y precursor de las universidades europeas, seguía expresando pareceres similares: "en el orden de la naturaleza, todas las cosas están subordinadas al hombre y han sido hechas para el hombre" (Santo Tomás, 2004, p. 104).

Pero como digo, es necesario rastrear ciertos pasajes de ambas tradiciones (judeocristianismo y filosofía occidental) para interpretar cómo el pensamiento político-filosófico entendió el contacto-conquista en 1492 y lo que supuso la interacción de ese "Occidente" con los pobladores de Abya-Yala, las relaciones asimétricas entre ambos y las repercusiones posteriores -dado ese inicio y esa configuración a la hora de ver el mundo- que tuvo en las relaciones naturaleza/cultura. Dichas relaciones nos han llevado, según varios investigadores, a un colapso civilizatorio que puede ser ya 
irreversible. Este colapso, además de llevar a riesgos planetarios que incluso ponen en entredicho la continuidad de la vida en el planeta tras el antropoceno, ha venido terminando con cientos de especies, a lo que se suma un proceso definitivo de cambio climático, desertificación y aumento de aridez de varias zonas del planeta, pérdida de biodiversidad, calentamiento global y expulsión de varias especies y de grupos humanos de sus hábitats, desde el Amazonas a Nueva Zelanda.

En este contexto se gesta -como algo inédito en la historia de la relación entre la Tierra y la Humanidad- una cada vez más compleja y profunda crisis ambiental provocada por la superación de los límites biofísicos como consecuencia del accionar de los seres humanos. Y es este proceso de sostenida destrucción de la sociedad y de la Naturaleza el que está poniendo en peligro la vida misma (Acosta, 2015, p. 23).

Y en el proceso de conformación del capitalismo, al que se une una racionalización técnica y la conformación del sistema de estados-nación (Gellner, 1988; Anderson, 1993), se produce asimismo la separación disciplinar del conocimiento con el fin de que este sea útil a la apropiación y expropiación de la naturaleza y la conformación de la clase burguesa como referente del nuevo orden post-medievo (Negri, 2008). La economía, como disciplina cuyo objetivo es distribuir bienes finitos, termina funcionan- do como un elemento más de dominación (Graeber, 2012) a través del cual se pretende orientar el destino del mundo. Incluso Foucault (2013) dirá que ese capitalismo es una especie de medioambiente en el que vivimos como el pez que solo conoce el agua y no puede salir de ella. Y desde esas visiones del sistema como hecho social total (y mundial), por ejemplo, se deriva la aceptación indiscutible del extractivismo incluso por parte de gobiernos progresistas, también neoliberales, en la actualidad (Acosta, 2015).

Observaremos, pues, cómo se ha conceptualizado la naturaleza desde la modernidad occidental, qué líneas de crítica han surgido en las últimas décadas en Latinoamérica y qué papel puede jugar una vertiente indigenista contemporánea para romper con la hegemonía eurocéntrica en el pensamiento a la hora de abordar las relaciones del ser humano con la naturaleza. El punto de arranque de estas lógicas es el siguiente: "quizá es la creencia más importante de toda la humanidad occidental, a saber: que el ser humano ocupa un lugar preeminente, superior y distinto a la naturaleza" (Maldonado, 2016, p. 42). Esto conlleva desde un pensamiento crítico, entre otros supuestos, exponer acerca de otras formas de entender la economía, ya no basadas en la sobrevaloración del valor de cambio por sobre el valor de uso, sino basadas en la complementariedad y la reciprocidad.

\section{NATURALEZA EN Filosofía OCCIDENTAL}

"La ciencia torture a la naturaleza, como lo hacía el Santo Oficio de la Inquisición con sus reos, para conseguir develar el último de sus secretos" (Francis Bacon, citado en Arrojo, 2010, s.p.). Tal como expone San- tiago Castro Gómez (1993) el proyecto de la modernidad tuvo dos ideas-fuerza como preceptos fundacionales para su acometida: por una parte (siguiendo a Blumenberg), colocar en el centro al hombre como principio 
ordenador frente a concepciones teológicas previas; y por otra, colocar a la naturaleza como gran adversario y enemigo al que hay que someter. Para ello, el papel de la razón-ciencia será fundamental. Pero previo a la racionalidad cartesiana-newtoniana de la modernidad, rompedora con respecto a la ciencia euclidiana, tenemos ciertos antecedentes en la filosofía griega.

Aristóteles (1280b-1281a. 2017) exponía en La Política que el "fin de la ciudad es, por tanto, el bien vivir, y todo eso [se refería a familia, territorio, amistad] está orientado a ese fin. La ciudad es la asociación de familias y aldeas para una vida perfecta y autosuficiente. Y esta es, como decimos, la vida feliz y bella" (p. 131). Para lograrlo, entre otras cosas, utiliza la metáfora-relato de la vida natural, según la cual hay hombres propensos a mandar y otros propensos a obedecer, justificando así las asimetrías de un marido con respecto a la mujer, con respecto a sus hijos y con respecto a sus esclavos domésticos; y de los súbditos con respecto a los ciudadanos, los cuales serán por definición libres, alegando que existe una esclavitud natural según la cual hay ciertas personas propensas por nacimiento a obedecer.

Si bien no se encuentra en Aristóteles teorizaciones contractualistas como las que utilizan Hobbes o Rousseau, ni tan siquiera la existencia de leyes naturales como las que exponen autores cristianos, sí existen en el pensador griego algunos rasgos precursores de la justificación de desigualdades humanas por naturaleza. Las implicaciones que ha tenido para poblaciones enteras colocar por encima y debajo de la línea de lo humano (Fanon, 2010) van de la mano de una acumulación originaria del capital: esclavos africanos substituyen a indígenas "america- nos" -dado su genocidio- en aras de extraer materias primas cuyas manufacturas sirven, entre otros aspectos, para iniciar la revolución industrial en Inglaterra. "Las 'razas superiores' ocupan las posiciones mejor remuneradas, mientras que las 'inferiores' ejercen los trabajos más coercitivos y peor remunerados." (Castro-Gómez y Grosfoguel, 2007, p. 16). Dichas posiciones se vienen jerarquizando desde la colonia con repercusiones hasta nuestros días.

Si hasta aquí observamos que poder, apropiación de recursos naturales y conocimiento técnico-científico van de la mano, el conocimiento que surgió en la modernidad, diferente al medieval y progresivamente cada vez más científico y laico, tiene en el cógito cartesiano una legitimación basada en sus raíces metodológicas; así como el papel fundamental de colocar al sujeto en el centro de la acción a la hora de llevar a cabo una aplicación de la teoría en la realidad social. A la dualidad objeto-sujeto, en la cual el científico-investigador devino un ente abstracto separado de todo tiempo y lugar, se suma las dualidades mente-cuerpo y cultura-naturaleza.

La naturaleza se convertiría en un campo de estudio e indagación, de domesticación y utilidad, lugar sobre el que accionar los saberes y los conocimientos en aras de una racionalidad técnica instrumentalizada. El objeto naturaleza es externa al individuo pensante. (Castro-Gómez, 1993, p. 154)

La extensión del método científico y los descubrimientos de nuevos mundos -en una época en la que corren paralelos la formación de un sistema de estados-, el inicio del capitalismo industrial y la progresiva separación científica de las explicaciones teológicas del mundo permitió a varios teóri- 
cos contractualistas, tras Descartes, separar mundo natural de mundo social. Independiente de la visión antropológica pesimista u optimista, tanto Rousseau, como Locke o Hobbes consideraban el paso de un estado natural a un estado social un avance de las sociedades mediado por la razón, la ciencia y la técnica. Por ejemplo, Locke (2016) expone lo siguiente:

Siempre que alguien saca alguna cosa del estado en que la Naturaleza la produjo y la dejó, ha puesto en esa cosa algo de su esfuerzo. Le ha agregado algo que es propio suyo; y por ello, la ha convertido en propiedad suya (...) Todo aquel que obedeciendo al mandato divino se adueñaba de la tierra, la labraba y sembraba una parcela de la misma, le agregaba algo que era de su propiedad (...) Las tierras que se dejan abandonadas a la Naturaleza, sin beneficiarlas en modo alguno con el pastoreo, el labrado o la siembra, reciben el nombre de yermos, y lo son en realidad, porque el beneficio que se obtiene de las mismas es poco más que el de un desierto estéril. (p. 62, 64, 71)

Más adelante, desde el punto de vista de Marx (1971, vol. III, p. 754), la relación tierra-renta (además de las relaciones entre trabajo-salario y capital-ganancia) "engloba todos los secretos del proceso social de producción." Según Marx, explotación social y explotación de la naturaleza van de la mano. Sin embargo, para el autor de El Capital, el campesinado no podría llegar a convertirse en clase para sí, papel que él centraba en el proletariado urbano-industrial, soslayando el papel que lo rural ha tenido y tiene en el devenir de una crítica radical a la explotación de la tierra.

Pero ya en los inicios del capitalismo industrial tenemos una separación urbano-ru- ral que Adam Smith (2016) supo exponer a la hora de analizar la división internacional del trabajo y las causas según las cuales unas naciones son más ricas que otras:

La política de algunas naciones ha estimulado extraordinariamente el trabajo en el campo; la de otras, el trabajo en las ciudades. Casi ninguna nación ha tratado de forma equitativa e imparcial a todas las actividades (...) La Política de Europa ha sido más favorable a las artes, las manufacturas y el comercio, actividades de las ciudades, que a la agricultura, el quehacer del campo. (p. 29, sus cursivas)

Por finalizar este breve recorrido, Max Weber (1984) dirá: "Solo en Occidente hay ciencia, una forma particular de arte; el Estado estamentario y parlamentos con representantes del pueblo [...] lo mismo ocurre con el poder más importante de nuestra vida moderna: el capitalismo" (p. 36-37). Según Weber, esto se debe al cálculo racional según el cual los individuos controlan el medio donde viven, algo que según él es propio del Norte Europeo y de EE.UU. Para Max Weber el proceso racionalizador es un "desencantamiento" del mundo. Ya no hay magia, ya no hay superstición, solo ciencia racional.

Sirva este breve resumen para constatar lo expuesto por Huanacuni (2010): "En la visión occidental está claro que una de las cosas más importantes es la generación de ganancias a partir de la explotación de la Madre Tierra. Y para el paradigma comunitario, el vivir bien se relaciona de manera preponderante y esencial con el sentido espiritual de la vida" (p. 24). A continuación se observan algunas líneas de fuga de esta visión provenientes de teóricos y comunidades latinoamericanos. 


\section{FRENTE AL EUROCENTRISMO Y AL UNIVERSALISMO: PROPUESTAS DESDE LATINOAMÉRICA}

En este apartado se sigue lo expuesto por Arturo Escobar (2014), quien afirma:

Las propuestas de algunos movimientos sociales (indígenas, afrodescendientes, ambientalistas, campesinos y de mujeres) sobre las cuestiones de tierra y territorio están a la vanguardia del pensamiento sobre estos temas (y de algunos otros, tales como la autonomía alimentaria, por ejemplo, y los modelos alternativos de desarrollo), y que no son rezagos del pasado, ni expresiones románticas que la realidad se encargará de desvirtuar. La mayoría de los conocimientos "expertos" desde el estado y la academia sobre estos temas, por el contrario, son anacrónicos y arcaicos, y solo pueden conducir a una mayor devastación ecológica y social. (p. 14)

Debemos remarcar el carácter de contemporaneidad de todos los habitantes de la tierra y no ver a ningún grupo, ni a sus propuestas de relación con el medioambiente como vestigios del pasado que se deben superar: "La modernidad se presenta como un privilegio de Europa, su creación propia y exclusiva, y oculta la colonialidad a la que fue condenada el resto de la población" (Marañón, 2014, p. 30). Diversos autores provenientes de la red modernidad/ colonialidad analizan las asimetrías generadas por un occidente eurocéntrico, el cual científica, política y económicamente pretendió universalizar la grilla de la modernidad diversificándola por todo el orbe. Esta pretensión universalista o "privilegio epistémico" (Grosfoguel, 2013) ha venido denostando las movilizaciones, derechos y acciones de muchos otros grupos, si bien, en un mundo cada vez más interconectado, la visibilidad y las posibilidades de trabajos en red critican el impacto de la homogeneidad y manifiestan los peligros de un pensamiento único que es, además de epistemicida en su formación, depredador de lo ecológico en su producción y reproducción. Significo la importancia de un pensamiento decolonial a la hora de comprender la depredación de la naturaleza por cuanto se hace necesaria:

Una educación decolonial e intercultural como un principio que orienta pensamientos, acciones y nuevos enfoques epistémicos, y que, más allá de denunciar el epistemicidio, deja en evidencia y reconoce esas otras formas de producción epistémica de resistencia, de insurgencia y de producción de alternativas al capitalismo, al patriarcado y al colonialismo globales (Sacavino, 2016, p. 103, mi traducción).

Pero el necesario proceso de cambio que va desde la utilización y la mercantilización hacia la conservación de la naturaleza pasa entre otros aspectos por un cambio de las racionalidades, de los imaginarios y de las cosmovisiones, lo cual está íntimamente ligado a una crítica y superación del eurocentrismo y del universalismo occidental. La Ilustración, la Modernidad europea y los saberes científicos y racionales que se configuraron en Europa propusieron una visión de la naturaleza basada en procesos biomecánicos y materialistas según los cuales, dicha naturaleza estaba en un plano jerárquicamente inferior a la cultura/civilización. En esa naturaleza estarían los animales, lo no europeo, el cuerpo, la mujer, el deseo, la emoción, etc. Lo útil, pues, es dominar ese campo colocado jerárquicamente en una capa inferior. 
En este sentido, desde diversos rincones del planeta se presentan propuestas teóricas que critican tanto al capitalismo como a la modernidad capitalista. Algunas se describen de forma breve con el interés de conocer cómo el dualismo naturaleza-cultura es una construcción eurocéntrica y qué propuestas y otras lógicas que expongan otras perspectivas se están planteando, desde la Academia, en íntima conexión con lo político y con los movimientos sociales. Una de ellas es la expuesta por Bolívar Echeverría (2008) y su propuesta de los ethe de la modernidad, según la cual la modernidad occidental europea es solo una de las posibles, dándose a lo largo de la historia en Latinoamérica movimientos y momentos de protesta y ruptura, en especial, desde lo que él denomina un ethos barroco en el cual unos códigos culturales (españoles) canibalizaron a otros (indígenas) a la vez que fueron canibalizados por ellos.

En este relato será central significar lo expuesto por Aníbal Quijano (1999). Según él, hay dos aspectos claves y entrelazados en la configuración de la modernidad capitalista: la subsunción de todas las formas de trabajo al capital y la idea de raza como fundante de las relaciones sociales, en lo que el autor denomina colonialidad del poder. Posteriores investigaciones propusieron que existen otras colonialidades como la colonialidad del ser, la colonialidad del saber y la colonialidad de la naturaleza. "Desde la Conquista, las diferencias se plantearon no como un asunto de poder, sino como una cuestión asociada a la "naturaleza" superior de los europeos respecto de "los otros" (López Córdova, 2014, p. 100). Por lo que respecta a la colonialidad de la naturaleza Katherine Walsh (2007), al realizar una crítica a los dualismos cartesianos, también expone que estos han negado a la naturaleza como cuerpo de la tierra, han eliminado las racionalidades indígenas y han soslayado que el ser humano es un ser vivo más dentro de dicha tierra-naturaleza. Incluso se expone que se ha creado un mito según el cual los saberes espirituales, chamánicos, indígenas, etc., son inferiores, subdesarrollados, arcaicos; vestigios de un pasado que el desarrollo, la educación, la asimilación y el progreso deben hacer desaparecer.

Pero antes del surgimiento de la red modernidad/colonialidad (Escobar, 2003), en Latinoamérica se cuenta con otros referentes teóricos que han sido críticos con las formas de entender la relación de la civilización occidental con la cultura. Con sus propuestas pedagógico-activistas (y si se quiere políticas y emancipatorias) Orlando Fals Borda expuso el concepto de "sentipensar" con la tierra. Según este concepto, a la hora de razonar no podemos caer en dualismos y asimetrías, sino que los procesos de análisis, interpretación y reflexión deben de ir de la mano del deseo, del corazón, de los sentimientos y de la raigambre con el medio en que vivimos. Para este autor, en cierto sentido precursor de la ecología de saberes desarrollada por Boaventura de Sousa Santos (2005, 2006), lo vivencial y lo racional van entrelazados desde una reflexión emanada del espacio local.

La ecología de saberes también sería una metodología novedosa que lucha contra las jerarquías, lo unilateral y las asimetrías a la hora de producir conocimiento. Su enfoque hacia lo diverso, lo múltiple y el diálogo tiene cada vez más acogida. Para lograrlo, conceptualiza una sociología de presencias y ausencias según la cual, históricamente hemos asistido a cinco monoculturas: del saber y del rigor, del tiempo lineal, de la naturalización de las diferencias, de la escala dominante y la productivista. Esta última 
trata sobre privilegiar la producción y primar el crecimiento económico como único objetivo racional; todo lo que no se sujete a esta lógica es declarado estéril si se trata de la naturaleza o improductivo si se trata de trabajo humano.

Frente a esta monocultura estractivista, Sousa Santos propone una ecología de las producciones (el plural es clave) que trataría de recuperar otros tipos de producción, cuestionando el desarrollo clásico y los modelos de acumulación y distribución predominantes. Al analizar comunidades indígenas y afro en Colombia, Quintero y Zamora (2017) ponen en práctica lo que Sousa Santos expone a nivel teórico, enfatizando el carácter participativo en la formación y reproducción del conocimiento y su utilización en la producción capitalista, no siendo utilizados los grupos minoritarios como meros objetos sino colocados en un plano de simetría con otros actores locales y globales. Al destacar "la importancia de reconocer la participación de las comunidades en la producción de conocimientos, no obstante, también existe la necesidad de garantizar que los beneficios generados por este ejercicio sean utilizados de manera justa, equitativa y concertada con todos los miembros de la comunidad". (p. 54)

Desde el Caribe, además de Frantz Fanon, Aimé Césaire en su Discurso sobre el colonialismo (2006, p.13) comienza diciendo que "una civilización que se muestra incapaz de resolver los problemas que suscita su funcionamiento es una civilización decadente". Dichos problemas los centra en dos: el proletariado y el colonial. La cita es algo extensa, pero recoge las consecuencias de la empresa colonial, la ambición de su proyecto, la mentalidad del conquistador occidental y las repercusiones planetarias:
¿Qué es, en su principio, la colonización? Reconocer que ésta no es evangelización, ni empresa filantrópica, ni voluntad de hacer retroceder las fronteras de la ignorancia, de la enfermedad, de la tiranía; ni expansión de Dios, ni extensión del Derecho; admitir de una vez por todas, sin voluntad de chistar por las consecuencias, que en la colonización el gesto decisivo es el del aventurero y el del pirata, el del tendero a lo grande y el del armador, el del buscador de oro y el del comerciante, el del apetito y el de la fuerza, con la maléfica sombra proyectada desde atrás por una forma de civilización que en un momento de su historia se siente obligada, endógenamente, a extender la competencia de sus economías antagónicas a escala mundial (Fanon, 2006, p. 14).

Y en esa extensión de competencias y crecimiento de escalas económicas planetarias incide una apropiación de los recursos. El propio Césaire, más adelante, (2006: 20) expone cómo se produce una cosificación, de vacío social, de culturas pisoteadas y de tierras confiscadas. Frente al pretendido progreso, el intelectual caribeño contrapone el desarraigo, la esclavitud y el servilismo de millones de seres humanos despojados en aras de dicho progreso colonizador.

Para cerrar este apartado se llama la atención sobre la propuesta realizada por lo que se ha denominado el perspectivismo amerindio, encabezada por Eduardo Viveiros de Castro y Phillipe Descola. Así, por ejemplo, Descola (2011) expondrá que el par naturaleza/cultura es una ficción, un artificio entroncado con el mecanicismo y el cientifismo de la modernidad. "La naturaleza no existe", no es autónoma, sino un constructo como la cultura o la sociedad, por ejemplo.

Varias propuestas expuestas hasta aquí centran sus análisis en comunidades locales, 
pequeñas, campesinas, rurales y/o indígenas para realizar una crítica al modelo occidental. Los intelectuales criollos han percibido al indio como parte de la naturaleza, pero también como un niño al que es preciso no sólo proteger sino decirle lo que debe ser y hacer. Previo a esto, con la expansión colonial, los pobladores originarios se asimilaron a "naturaleza". Posteriormente, en la época republicana y en décadas posteriores, según Villegas (2013) se produjo una idealización del pasado indígena que sirvió para realizar una crítica a los tiempos presentes, los cuales son vistos como una decadencia de la armonía primigenia y ancestral: "los ancestros de los actuales indígenas fueron vistos como capaces de crear grandes civilizaciones; por el contrario, los indígenas actuales sólo pueden ser caracterizados como perezosos, sucios, borrachos, incivilizados e iletrados" (p. 7).

Frente a esta visión denostadora de poblaciones asentadas en tierra latinoamericana desde hace milenios, surge la visibilización de diversas comunidades que con sus luchas, protestas, búsquedas de recursos y defensa de derechos han conseguido entrar en diferentes agendas políticas nacionales e internacionales. Su cosmovisión y espiritualidad es central en un acercamiento para comprender la naturaleza ya no bajo una perspectiva expoliadora y depredatoria, sino en un plano holístico e integrador con el medio ambiente, y con los mundos animal, humano y espiritual.

Un ejemplo de esta visión es la propuesta llevada a cabo por los gobiernos progresistas de Ecuador y Bolivia en años recientes y se ha denominado Buen Vivir, como traducción del quechua sumaq qamaña y del aymara sumak kawsay. "El Buen Vivir es una alternativa orientada a tratar de rehacer la vida socioambiental a partir de la solidaridad humana y con la naturaleza, no solo en la actividad económica y productiva, sino en todas las dimensiones de la existencia social: el trabajo, el sexo, la autoridad colectiva, la subjetividad y la naturaleza" (Marañón: 2014, p. 41). En este sentido, las propuestas políticas que surgen en estos gobiernos progresistas oponen una resistencia a las contradicciones, irracionalidades y consecuencias perversas del capitalismo basado en el extractivismo y el despojo.

Por ejemplo, en la constitución de Ecuador, en su artículo 71, se refiere que: "La naturaleza o Pacha Mama, donde se reproduce y realiza la vida, tiene derecho a que se respete integralmente su existencia y el mantenimiento y regeneración de sus ciclos vitales, estructura, funciones y procesos evolutivos".

\section{Conclusiones}

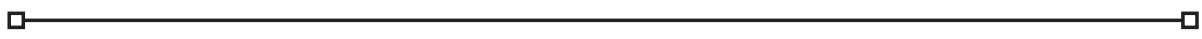

Desde el punto de vista de Huanacuni (2010) el año 2009 supuso una brecha para dejar de lado la explotación de recursos y abrirse hacia una vida que respete el equilibrio de todas las formas de vida del planeta: "El 22 de abril del 2009, la Organización de Naciones Unidas (ONU) acogió la iniciativa impulsada por la delegación boliviana y de- claró a esta fecha el día internacional de la Madre Tierra" (p. 9). Según el intelectual y activista boliviano, este hito permite generar una conciencia acerca de que la tierra no solo es un planeta más, sino que es nuestra madre tierra (Pachamama). Pero el camino hacia ese proceso de concientización y que no quede simplemente en enunciados polí- 
ticos conmemorativos es arduo, para nada está finalizado y requiere una constante reconstrucción y reflexión acerca de las asimetrías y contradicciones manifestadas por más de 500 años de formación y auge del capitalismo, en su conceptualización de la utilidad de la naturaleza.

Según Ramón Grosfoguel (2016), “El problema con el concepto de 'naturaleza' es que sigue siendo un concepto colonial, porque la palabra está inscrita en el proyecto civilizatorio de la modernidad" (p. 129). Este autor argumenta cómo otras cosmovisiones diferentes a la occidental no conciben a la naturaleza como un objeto, sino como un sujeto que se interrelaciona con otros muchos, tanto humanos como no humanos; y enfatiza que dicho concepto de naturaleza implica una división entre lo humano que se percibe como sujeto frente a una cosificación de la naturaleza (objetivada), la cual se percibe como inerte y que "por consiguiente, sus formas de vida son inferiores a la humana y están inscritas en la lógica instrumental de medios-fines de la racionalidad occidental donde la 'naturaleza' se convierte en un medio para un fin" (p. 129).

Según estas cosmovisiones, el capitalismo necesita someter tanto a sus "otros" como a la naturaleza. Tanto es así que incluso en ocasiones naturaliza a sus otros, folclorizando, exotizando, esencializando.

La relación espiritual, animista con la naturaleza es propia de muchos pueblos, en particular, cazadores, recolectores y pescadores. Las montañas, los ríos, los animales, en fin, todo lo que para Occidente es externo y objeto de manipulación o explotación, en las culturas indígenas aparecen como viviente y en permanente relación de reciprocidad con el ser humano (Bengoa 2000: 137, cit. en Bedoya, 2015, p. 149).
Quizá uno de los puntos de arranque fundamentales sea concienciar acerca de las potencialidades de la diversidad, la interculturalidad y la transdisciplinariedad como ejes axiales frente a la ontopolítica de lo Uno (un territorio, a conquistar; una población, a expropiar; un estado, a controlar; una única forma económica globalizadora y globalizante: el capitalismo) desarrollada desde la modernidad occidental. Las últimas décadas, desde el famoso discurso del Presidente Truman en su toma de posesión en 1949, han sido los años del desarrollo, en donde se trataba de llevar a cabo un "trato justo" a áreas subdesarrolladas que no deberían sufrir las consecuencias de la desatención post segunda guerra mundial. Con ese discurso se inició una época de una enorme incidencia de tres factores (capital, tecnología, conocimiento experto) que han tenido devastadoras consecuencias, debido al asistencialismo, paternalismo o dejadez, dependiendo del caso y la situación, por parte de gobiernos occidentales y mercados globales en zonas pauperizadas precisamente por dicho desarrollo. Frente a estos procesos Escobar (2014) llama la atención acerca de las múltiples luchas que se dan en todo el orbe para defender paisajes y territorios, siendo dichas luchas motivadas y consecuencias de un modelo uniforme de entender el mundo: "Moderno/capitalista, secular, racional y liberal con su insistencia en la ilusión del "progreso" y el "desarrollo"" (p. 21, sus comillas). Según este autor, la medida de las acciones humanas hoy en día está basada, por una parte, en el consumo individual; y por otra, en la competitividad del mercado. Como consecuencia, la intervención de ciertas economías en varias zonas del planeta lleva a generar la idea de poder transportar modelos "exitosos" a otras zonas del orbe sin tener en cuenta factores demográficos, culturales y/o físicos. Este hecho ha resul- 
tado perjudicial, ha aumentado el extractivismo y ha generado lo que Naomi Klein (2007) denomina "doctrinas del schock" creadas ad hoc en lugares a intervenir en aras de ese progreso deseado (disfrazado de justicia, democracia, libertad, etc.).

Cuando diferentes movimientos campesinos $\mathrm{y} / \mathrm{o}$ indígenas entran en conflictos y demandas por sus tierras se contesta por parte de la sociedad envolvente que no se les puede conceder porque no son del todo indios (por ejemplo, porque usan teléfono móvil, porque asisten a escuelas bilingües, porque realizan trabajos en espacios citadinos, etc.). Pero construir la ciudadanía es a la vez una forma de construir la democracia, de ampliarla, ante lo cual observamos que los modelos de reciprocidad y sostenibilidad con el ambiente son más integradores por parte de las cosmovisiones de pueblos originarios que si nos basamos en el individualismo/desarrollismo occidental. Debido a la crítica y resistencias frente al sistema capitalista occidental, varias minorías étnicas aportan al debate actual formas sociales y económicas que no deben de ser ni excluyentes ni excluidas.

Ya que inicié este recorrido con la Grecia Clásica, fuente de la democracia, finalizo con la importancia del referéndum en lo que a las problemáticas del planeta atañe:

El hombre primitivo ha vivido dos veces: una para sí mismo y la segunda para nosotros, en nuestra reconstrucción (...) Después de que los principios de nuestro propio orden social se hayan convertido en asunto de debate continuo, ha habido una tendencia a recurrir al primer hombre para que resuelva nuestras disputas por nosotros. Su voto en las próximas elecciones generales es solicitado con entusiasmo (Goody, 1994, p. 24).

Pero dicho voto (derecho político) no puede alejarse de otros derechos básicos como los comunitarios, los territoriales y los de vida digna en torno a sus territorios ancestrales. El despojo, usurpación y movilización al que han sido y son sometidos diversos grupos subalternos pone en tensión la acumulación capitalista con el respeto a la vida digna propugnado, cada vez más, en acuerdos internacionales y ratificado en diversas constituciones nacionales. La relación entre la cosificación a la que se ha sometido la naturaleza y la cosificación de poblaciones enteras -vistas como materia prima y mano de obra barata desde la modernidad occidental- hacen necesarias otras alternativas a la modernidad eurocéntrica como algunas de las aquí señaladas.

\section{Notas}

口-

1. Visto en http://www.mundoobrero.es/pl.php?id=1515\&sec=3, consultado 31/07/2019

2. Se puede observar este programa pedagógico y los textos que trata en el siguiente enlace: https:// artesliberales.uai.cl/core-curriculum/

3. Entrevista de Gerard Coffrey a Descola en La Línea de Fuego, 16 de mayo de 2018. Consultado 29 de mayo de 2018: https://lalineadefuego.info/2018/05/16/philippe-descola-y-los-achuar-la-naturaleza-no-existe-entrevista-de-gerard-coffey/ 


\section{REFERENCIAS}

Acosta, A. (2015). Las ciencias sociales en el laberinto de la economía. Polis $N^{\circ} 41$ (2015): 21-42.

Agustín (Santo, Obispo de Hipona) (2004). Ciudad de Dios. Traducción: Santos Santa, M. del R. y Fuertes, M. Madrid: Biblioteca de Autores Cristianos.

Anderson, B. (1993). Comunidades imaginadas: reflexiones sobre el origen y la difusión del nacionalismo. Buenos Aires: Fondo de Cultura Económica.

Aristóteles (2017). La politica. Santiago de Chile: Liberalia Ediciones. Edición especial "Programa Core UAI".

Arrojo, P. (2010). "El reto ético de la crisis global del agua", en Acosta, A. y Martínez, E. (comp.) Agua-Un Derecho Humano fundamental. Quito: Abya Yala. pp. 281-328.

Bedoya, V. A. M. (2015). Existencia equilibrada. Metáfora del Buen Vivir de los pueblos indígenas. Polis: Revista Latinoamericana, 14(40), 143-163.

Castro-Gómez, S. (1993). “Ciencias sociales, violencia epistémica y el problema de la 'invención' del otro". En La colonialidad del saber: Eurocentrismo y Ciencias Sociales. Perspectivas latinoamericanas. Buenos Aires: CLACSO.

Castro-Gómez, S., \& Grosfoguel, R. (2007). Prólogo. "Giro decolonial, teoría crítica y pensamiento heterárquico". En Escobar, A. (2007) El giro decolonial. Reflexiones para una diversidad epistémica más allá del capitalismo global. Bogotá: Siglo del Hombre

Césaire, A. (2006). Discursos sobre el colonialismo. Madrid: Ediciones Akal.

De Aquino, Santo (2017). Suma de Teología (selección). Madrid: Biblioteca de Autores Cristianos.

Descola, P. (2011). "Más allá de la naturaleza y la cultura", en Montenegro, L. (Ed.) Cultura y naturaleza. Bogotá, Jardín Botánico José Celestino Mutis.

Echeverría, B. (2008). El ethos barroco y los indios. Revista de Filosofia "Sophia, 2. Acceso: https:// flacsoandes.edu.ec/sites/default/files/agora/files/1260220574.elethos_barroco_y_los_indios_0.pdf

Escobar, A. (2014). Sentipensar con la tierra. Nuevas lecturas sobre desarrollo, territorio y diferencia. Medellín: Medellín: Ediciones UNAULA.

Escobar, A. (2003). "Mundos y conocimientos de otro modo. El programa de investigación de modernidad/colonialidad latinoamericano". Tabula Rasa, (1), 51-86.

Fanon, F. (2010). Piel negra, máscaras blancas. Madrid: Akal.

Foucault, M. (2013). El poder, una bestia magnifica. Sobre el poder, la prisión y la vida. México D.F: Siglo XXI Editores. 
Gellner, E. (1988). Naciones y nacionalismo. Madrid: Alianza.

Graeber, D. (2012). En deuda. Barcelona: Ariel.

Goody J. (1994) El Arado, La Espada y el Libro. La Estructura de la Historia Humana. Barcelona: Editorial Península.

Grosfoguel, R. 2016. Del «extractivismo económico» al «extractivismo epistémico»y al «extractivismo ontológico»: una forma destructiva de conocer, ser y estar en el mundo. Tabula Rasa, 24

Grosfoguel, R. (2013). Racismo/sexismo epistémico, universidades occidentalizadas y los cuatro genocidios/epistemicidios del largo siglo XVI. Tabula Rasa, 19.

Huanacuni, F. (2010). Buen Vivir/Vivir Bien. Filosofía, políticas, estrategias y experiencias regionales andinas. Lima: Coordinadora Andina de Organizaciones Indígenas.

Klein, N. (2007). La doctrina del schock. El auge del capitalismo del desastre. Barcelona: Paidós Ibérica.

Lenkersdorf, C. (2010), Diccionario español-tojolabal. Idioma mayense de Chiapas, 2, Instituto de Investigaciones Filológicas, UNAM, México D.F., <http://www.rebelion.org/ docs/123767.pdf>, 09 de abril de 2018.

Locke, J. (2016). Segundo tratado sobre el gobierno civil. Un ensayo sobre el verdadero origen, alcance y fin del gobierno civil (selección). Santiago: Liberalia ediciones. Edición Programa CORE UAI.

López Córdova, D. (2014). "La reciprocidad como lazo social fundamental entre las personas y con la naturaleza en una propuesta de transformación societal”. En Marañón, B. (coord., 2014) Buen Vivir y descolonialidad. Crítica al desarrollo y la racionalidad instrumentales. México D.F: UNAM.

Maldonado, C. E. (2016). Pensar con la naturaleza. Una idea radical. Uni-pluriversidad, 16(2), $42-51$

Marañón B. (2014). "Crisis global y descolonialidad del poder: la emergencia de una racionalidad liberadora y solidaria”. En Id (coord., 2014) Buen Vivir y descolonialidad. Crítica al desarrollo y la racionalidad instrumentales. México D.F: UNAM.

Marx, C. (1971) El capital. Crítica de la economía política. México: Fondo de Cultura Económica.

Negri, A. (2008) Descartes político. Madrid: Akal.

Quintero Rodríguez, D. y Zamora, N. (2017). Una aproximación al concepto de apropiación social del conocimiento: desde los conocimientos tradicionales de las comunidades afrocolombianas e indígenas. Uni-pluriversidad, 17(1), 50-58. 
Quijano, A. (1999). “Colonialidad del poder, cultura y conocimiento en América Latina”, en: S. Castro-Gómez, O. Guardiola-Rivera, C. Millán de Benavides (eds.), Pensar (en) los intersticios. Teoría y práctica de la crítica poscolonial. Santafé de Bogotá: CEJA, p. 99-109.

Sacavino, S. (2016). Tecidos feministas de Abya Yala: Feminismo Comunitário, Perspectiva Decolonial e Educação Intercultural. Uni-pluriversidad, 16(2), 97-109.

Santos, B. de Sousa (2005). El milenio huérfano. Ensayos para una nueva cultura politica. Madrid, Trotta.

Santos, B. de Sousa (2006). Renovar la teoría crítica y reinventarla emancipación social: encuentros en Buenos Aires. Buenos Aires, CLACSO.

Smith, A. (2016). La riqueza de las naciones(selección). Santiago: Liberalia ediciones. Edición Programa CORE UAI.

Villegas, L. F. B. (2013). Ecuador siglos XIX y XX. República, 'construcción’del indio e imágenes contestadas. Gazeta de Antropología, 29(1): 1-23.

Walsh, C. (2007). ¿Son posibles unas ciencias sociales/culturales otras? Reflexiones en torno a las epistemologías decoloniales. Nómadas, (26), 102-113.

Weber, M. (1984). La ética protestante y el espiritu del capitalismo. Madrid: Editorial. 